\title{
'Without my faith I would break into pieces.' Supporting elder family members: Implications for social work policy and practice
}

\author{
Judy Wivell and Diane Mara
}

Judy Wivell is a Social Work Lecturer; Social Work Stream Coordinator, BASS and Diane Mara is a Project Leader: Commissioned Research; Early Childhood Lecturer.

\begin{abstract}
This collaborative project records the voices of family/ whanau members most closely involved with the responsibility for support of elder parents or family members. Members of the research team are from two different cultural backgrounds and have worked within and across both cultural paradigms investigating Pakeha/European and Pasifika family / fanau structures. The small-scale study sought to identify patterns of similarity and difference in approaches to family decision-making, how families access appropriate social services, and what changes occur in family dynamics as they respond to elder family members' needs. This research has required engagement with members of diverse communities about an often invisible aspect of family life in Aotearoa New Zealand. The support of elders by adult children is expected to become more prevalent across communities with the aging of the population and the widening cultural diversity of families. Key themes emerging from the participants' reported experiences have the potential to inform social service practice and social policy and these are highlighted.
\end{abstract}

\section{Introduction}

The geographical contexts of this study were two provincial areas where the researchers were able to involve members of a Pasifika community and Pakeha/European as participants. The voices from two different ethnic groupings were sought as was the opportunity to explore the commonalities and differences between these two groups. Further, this research went on to consider the potential impact of the participants' experiences on policy and practice. Both provincial areas are characterised by increasing cultural diversity and a general ageing of the population.

A growing and developing focus on the care and support of elderly family members by their adult children is becoming apparent across all sections of the community. Commenting on informal care and changing social contexts, Belgrave and Brown (1997) discuss the need for reappraisal regarding support for elder family members, 
... amidst changing social and demographic trends which include the ageing population, the return to the workforce by increasing numbers of women, and changes to the nature of the family and the household structure (p.3).

This growing focus on the support of elder family members impacts on relationships within the family. Petrie (2006), writing about the ageing population and potential impacts within families, says that,

We are interested in flows both upward and downwards between different generations in an extended family, and we are interested in all types of interaction (p. 309).

The aim of this small-scale study was to expand our knowledge and understanding of current family dynamics and family decision-making. In so doing we hoped to gain further insight into cross-generational relationships and family dynamics, associated with aspects of elder care and support.

The impetus behind this study arose from professional conversations and a desire to research a topic of mutual interest that combined knowledge and experience in Pacific community development on the part of one researcher and in social work pedagogy and practice on the part of the other.

\section{Research methods and approach}

This was a qualitative ethnographic study in which the lives of adult family members and their reported experiences whilst taking responsibility for and supporting their elderly parent or relative are foregrounded.

A full research proposal was developed and ethics approval was sought and gained from the EIT Research Approvals Committee prior to commencing the study.

The lead researchers are of Pakeha and Pasifika cultural heritages. An additional field researcher from the local Pasifika community assisted the Pasifika researcher with those interviews and with the organisation of the Pasifika focus group. Pasifika Research Guidelines (Anae, Coxon, Mara, Wendt-Samu \& Finau, 2001) were closely followed during this study to ensure the appropriate protocols and values underpinned our relationship with our Pasifika participants.

Participants were recruited using the snowball approach and they needed to meet the criteria for being an adult family member who had recently, or who were currently, supporting an elder parent or relative in the home. The individual interviews all involved female adult children except for one Pasifika male caring for his mother. In the focus groups two couples (one Pasifika and one Pakeha family) were involved. The balance of the membership of both focus groups was female. Information on age of participants or their elder was not collected. All Pasifika participants identified as Cook Islands Maori.

Two main methods of data collection were employed: individual semi-structured interviews and focus groups (Denscombe, 2007, p. 78). Individual face-to-face interviews with semi-structured questions were chosen because it was anticipated that the focus of the interviews would be a very emotional one for the participants as they talked about their 
dependent elder and as they shared their family stories and histories. In several cases the individual interviews proved to be an appropriate and supportive approach for participants. In terms of the focus group approach, one focus group was held for Pasifika and one focus group for Pakeha/European involving additional participants to those interviewed individually. In one instance we were able to visit a support group of adult children with aged family members that had already been formed. The focus groups were co-facilitated by both researchers, and participants were encouraged and supported to begin talking, finishing with tea, coffee, milo and supper.

The range of topics covered in the semi-structured interviews and the focus group included: the circumstances under which family members became responsible for their parent or elder; how this responsibility affected family dynamics or relationships; the nature of the resources or sources of support available to them in this role; what sources have been most helpful and what would have been ideal for their family situation; and, what strengths, skills or qualities had been gained as a result of this responsibility.

It was expected that both of the chosen methods would together yield rich narrative data and provide more in-depth understanding of family roles and responsibilities, family relationships and decision-making strategies. Although the participant sample was small there was a significant consistency between the stories of the adult children in the narratives from the individual interviews with those recorded in the focus groups.

The congruent themes that emerged included: the reasons a child takes responsibility for an elder family member; the types of life changes that were occurring for both the elder family member and the adult child and the interaction of these changes; the family patterns and decision-making processes that were evident as the child journeyed through this part of life; the strengths that were drawn on and developed as a consequence of this experience; and the strategies for accessing appropriate social services.

\section{Results and discussion}

Six main themes emerged from the narrative data. These are described using direct quotes and incorporating some insights sourced from the literature as appropriate.

\section{Reasons for taking responsibility for an elderly family member}

Pragmatism was cited as the reason for taking responsibility for an elder family member, particularly when the participant lived nearby. However, this was underpinned with a sense of loyalty, family responsibility and duty. One participant who lived in the same neighbourhood as their elderly parent described their motivation as, 'doing things out of a sense of duty and an intense feeling that they (the elderly parent) had a right until their last breath to be treated with respect and love and kindness'. Strong values and beliefs were intertwined with the practical considerations and there were a number of comments about the importance of going the extra mile for their parent or elder. The following remark depicts this sentiment, 'She/he gave up heaps for me and put me through university, wasn't easy, no one in her family had been to university ... I can do it for her now that she needs me'. There was also a cultural perspective for taking responsibility for an elderly parent. One participant made the point, 'We do this because of our culture. We look after our old people, no matter how tough it is'. 


\section{Life changes and life stages}

Roles and relationships changed particularly as elderly parents became more and more frail and one participant reflectively explained, 'We begin life as a child then become friends with our parents and finally a parent to the parent'.

\section{As Horne (1991) notes:}

... a relationship between an adult child and parents has history, which they continue to create until death parts them ... Regardless of the frailty or impairment of the parent, the adult child will always be his child, a fact that colours every aspect of caregiving (p.105).

Managing life changes with an elder family member was a struggle. Participants wrestled to find the balance between guiding and controlling, and part of the journey was 'learning to gently steer rather than taking over their elderly parents' lives'.

Amongst the participants there was minimal discussion about financial impacts, such as the cost of providing transport and meals and the following comment substantiates this, 'It is not the practical decisions that are going to catch us out in the future; it's dealing with the emotional stuff'.

There was frequent reference to the range of emotions experienced. Being able to attend to and reconcile these feelings took time. As one participant said, '... it wasn't overnight or anything startling like that, it took time, but I found right at the end I was more than happy to just go and enjoy (her), there was nothing more I could do that would make it better'.

Arriving at a point of resolution was not a process that could be hurried and may take many months rather than days. Dealing with change was painful and participants shared generously about this including describing how it is difficult to have a parent alive, but unwell. One participant described the situation in this way, 'Not having Mum to talk to is hard - can't even ask her about other family members - even though she is alive'.

Adding to the complexity of participants' experiences was recognising and dealing with the impacts of the life transitions and associated feelings that the elderly people themselves are experiencing. Hambleton and Keeling (2008) in their study of the perceptions of older people receiving low-level home support say that, 'Participants spoke of the loss of important people in their lives and of varying degrees of physiological functioning' (p.154). At times it appeared that for elder family members and their children the only constant was change.

Some participants were self condemnatory and were challenged by their own negative feelings when actions conflicted with strongly held beliefs about the right to 'care and comfort'. Several talked about how they had not expected to be caring at a time in their lives when they expected to have freedom. One participant said, 'I feel I am the centre of her world now which I'd rather not be' and then went on to share about her commitment and love for her parent.

The role of being an adult child taking responsibility for an elderly family member provided challenges and while we have all been children, adult children have yet to experience being the elderly parent (Horne, 1991). For some their perception of, '... being caring and kind and loving elderly people was seriously dented (especially when tired)'. Participants 
talked about the stress of managing their own life stages as well as carrying the load for their parents' transitions. As one participant said, 'I think I hide the stress... I think my prayer really helps me, without God I would break into pieces'. Emotions tended to be juxtaposed: love and dislike, patience and anger, loyalty and resentment, sadness and lightheartedness and participants experienced an ongoing emotional roller coaster ride.

\section{Family patterns and dynamics}

Relationships were highly valued and participants' stories were situated both in the past and the present. Keeping the focus on the needs of the elder family member was the priority even when stress and tensions increased. Fanau made space for the elder family members. This space may have been physical, e.g., setting up a bed in the lounge so the elderly parent could be near family, but it also included spiritual and emotional 'space' at a time of increasing dependency.

The pre-established family patterns and dynamics continued and they did not appear to change significantly as the elder family member aged. For example, the child who was always perceived as the 'spoilt sibling' of the family continued to be cast in this role and the sibling who was labelled as 'bossy' when they were a child, was still in charge!

Family patterns were unique and different and siblings worked with their elderly parent in different ways. For example, some family members openly acknowledged to the adult child who was taking on most of the responsibility that they were simply unable to deal with the ageing process of their elderly family member. At times these siblings offered support, sometimes in practical ways such as financial support.

\section{Decision making}

This is closely connected to family dynamics but deserves its own space and discussion because this was an area that caused a great deal of stress for most of the participants. Thoughts about the elder family member were never far from the adult child's mind. Their stories reflected a sense of walking a tight rope between empowering the elderly parent to make decisions and determining when they needed to make the decision on behalf of the parent.

Involving family members in decision making was often difficult and complex and was spoken about in the following way by one participant,

They (siblings) don't want any responsibility for what happens day to day...They are supportive from a distance but we keep in close contact ... We make sure that they are involved in every decision even though they don't want responsibility for it.

Participants respected their elder family member's wishes to have family members involved. This was true even when the relationships were challenging.

\section{Strengths and resilience}

For all participants existing strengths were enhanced and new strengths discovered as they became intimately involved with an elderly parent. Their strengths were woven into their stories and included:

- Problem solving and overcoming struggles effectively. Participants talked about being organised, thinking outside the box for solutions to difficulties, consulting and negotiat- 
ing with family and those involved in service provision in the elderly family member's life.

- Making the older person a priority and juggling competing demands on time and energy.

- Ongoing commitment over a period of time and building and sustaining relationships both within the family and also with outside networks.

- Finding creative and healthy ways to unwind, resilience in times of stress and an attitude of just getting on with it. This strength was aptly described when one participant said, 'There are always barriers...keep positive, have breaks, bring people over to talk to your elder...keep your sense of humour, happiness is part of the healing'.

- Faith and spirituality and the important role it played in their journey with their elder parent.

- A willingness to learn tolerance and patience and to go to the hard places in relationships including forgiveness. As one participant poignantly explained 'I suppose for me to do the role that I'm doing now I actually had to learn to forgive ... to be in that role and be supportive, you actually have to let go of it, of stuff that happened in the past, to forgive'.

\section{Accessing appropriate social services}

A 'trial and error' process in accessing appropriate services was a common comment. Some participants knew a few key resources but it was only as the journey unfolded that their resource base grew. At times they didn't know where to look for resources or what resources would be most helpful for their elderly parent. Knowing the questions to ask was sometimes difficult too. Some were confident about asking questions and requesting support while others were more diffident.

The difference between the two ethnic groupings was readily discernible in this area. Pakeha children played an active advocacy role and had some knowledge of relevant systems. Pasifika fanau had wide fanau networks to call on which was helpful in spreading the load, but the use of social services and external networks did not feature so strongly. The reasons for this were difficult to ascertain.

Ray, Bernard \& Phillips (2009) make the point that, 'Members of the minority ethnic communities may be rendered effectively invisible by services that are, in reality, geared to the needs of the dominant population' (p. 62). They further suggest that this problem may well be magnified for populations who have experienced racism through their life span (Ray et al., 2009) and this may be a possible reason for making less use of formal social or health services.

The Pasifika participants were reticent and less confident about going outside the family for support because of family obligations. Schofield et al. (2006) note that,

Cultural affiliations shape personal identity, attitudes to life and expectations ... For instance, shame attached to disability and high expectations of kinship care that are culturally based act as deterrents against older Pacific people in poor health seeking help outside the family (Huakau and Bray, 2003, cited in Schofield et al., 2006, p. 284).

While this comment is about older people seeking help for themselves outside the family it was true also for the Pasifika adult children we interviewed, except in one case. In this fanau 
the participant talked about reluctantly putting their father into residential care because he had dementia and, in addition, because their mother was also ill the load the siblings were carrying was overwhelming. The family were unexpectedly surprised and pleased with the care and the 24-hour access they were permitted to have to their father. They also felt they could speak to the staff, 'If we are unhappy about Dad's care we talk to them'. One sister was employed at another residential care facility for the aged so she felt confident about asking questions due to her knowledge of quality service standards and expectations.

\section{Implications for social service practice and social policy}

From this study, albeit small in size, it became evident that there are a number of key areas relevant to both practice and policy including: family decision-making, accessing social services, families as stakeholders in the development of policies and services, workforce participation and understanding, and working with the implications of diversity.

\section{Family decision-making}

The participants reported that they made the effort to keep in touch with siblings, signalling the importance of sharing information and decisions and where appropriate holding family meetings. Physical distance separating children and elderly family members was considered to have a significant impact on families by some participants. The role of technology in enhancing communication and connectedness between family members is an area to be pursued more fully.

An active approach to supporting and resourcing relevant family meetings may help fanau, including the elder family member, work effectively together to develop and maximise skills, resources and knowledge. However, this needs to be tempered with the acknowledgment that families have historical as well as current biographies that must be taken into account. Ray et al. (2009) note that, 'The relationship that carers have with the person they care for will be individual and located in their biography and life course' (p. 115). At the heart of family decision-making is the family's own context.

\section{Accessing support and resources}

Ways to minimise the struggle to find and implement appropriate resources for elder family members is a challenge for both policy makers and social services. This is particularly true for the Pasifika community. Hambleton and Keeling (2008), in their research with older recipients with low level home care support, make the point that there appeared to be a lack of awareness about the options for support and while their participants were the elderly the same comment could be applied to the participants of this study. Such lack of knowledge about the range of supports available is counterproductive in an era when 'ageing in place' is a predominant concept.

\section{Families as stakeholders in policy and social service development}

Just as participants in this study grappled with what it means to be an adult child and to work inclusively with their elderly parent, practitioners and policy makers also need to ensure that all voices are heard. Attending to the power differences between the various people, e.g., elder person, adult child, caregivers, social workers and nurses, is a significant practice issue and may give rise to ethical dilemmas. Multiple agendas may clash and relevant ways to support families and ensure that all voices are heard, including the elder family member, 
need to be found. Sennett's description of the tenuous relationship between care and control as 'a membrane so porous ... that it dissolves at the slightest touch' (Sennett, cited in Paul, 2009 , p. 34) captures the struggle experienced by participants.

\section{Family circumstances: workforce participation}

Adult children are frequently in some form of employment, and have a range of family and community commitments. Petrie (2006) notes,

Population ageing may have direct implications for families due to its impact on intrafamily relations. It may also have indirect implications through its macro effects on non-family institutions, for instance, by creating fiscal pressure that is manifest through a change in state assistance to individuals and families (p. 309).

Resourcing appropriate leave and support for those involved with their elderly family member to go to appointments, provide transport and so on, has yet to be comprehensively addressed in Aotearoa New Zealand. Schofield et al. (2006) referring to the changing landscape for families state that, 'Growing levels of workforce participation among the generation of adult children who support older people to age in place highlight the need to accommodate working carers' (p. 295).

\section{Recognition of the implications of diversity}

Recognition of the diversity of families and the range of different needs a family may have is pivotal. It is important for assessments and planning to be negotiated and resourced and for social service workers to be skilled and equipped to deal not just with the practical concerns of the elderly family member but also with the struggles of the adult child as they face constant competing demands and at times emotional turmoil.

In conclusion, flexible and inclusive strengths-based practice, together with responsive policy and resourcing in the area of elder support and support for elder carers within families and fanau would be advantageous for the families in this study and even more so for others whose voices are yet to be heard.

\section{References}

Anae, M., Coxon, E., Mara, D., Wendt-Samu, T., \& Finau, C. (2001). Pasifika education research guidelines. Wellington: Ministry of Education.

Denscombe, M. (2007). The good research guide for small-scale social research projects (3rd ed.). England: Mc Graw-Hill Open University. (Focus Groups pp. 78-183).

Belgrave, M., \& Brown, L. (1997). Beyond a dollar value: Informal care and the northern region case management study. Auckland: North Health, Massey University, Waitemata Health.

Hambleton, P., \& Keeling, S. (2008). The quality of life is ... : The views of older recipients of low-level home support. Social Policy Journal of New Zealand Te Puna Whakaaro, 33, 146-142.

Horne, J. (1991). A survival guide for family caregivers. United States: CompCare Pub.

Jack, R. (2005). Strengths-based practice in statutory care and protection work. In M. Nash, R. Munford, \& K. O'Donoghue (Eds.), Social work theories in action (pp.174-188). London: Jessica Kingsley Publishers.

Office for Senior Citizens, (2001). The New Zealand positive ageing strategy: Towards a society of all ages. Wellington: Ministry of Social Policy. Retrieved, 19 August 2008, from http: / / www.osc.govt.nz / positive-ageing-strategy / publication/ executive-summary.html

Paul, C. (2009, August 15). A question of compassion. Listener, pp. 33-34.

Petrie, M. (2006). Implications of population ageing for families. In J. Boston \& J. A. Davey (Eds.), Implications of population ageing: Opportunities and risks (pp. 307-335). Wellington: Institute of Policy Studies Victoria University.

Ray, M., Bernard, M., \& Phillips, J. (2009). Critical issues in social work with older people. London: Palgrave Macmillan. 
Schofield, V., Davey, J. A., Keeling, S., \& Parsons, M. (2006). Ageing in place. In J. Boston \& J. A. Davey (Eds.), Implication of population ageing: Opportunities and risks (pp.275-306). Wellington: Institute of Policy Studies Victoria University.

Wivell, J. \& Mara, D. (2009). The impacts on adult children of family and fanau responsibility for elder family members: Cross-cultural perspectives. In H. Hamerton \& C. Mercer (Eds), Research that works: Successful collaborations (pp 74-78). Proceedings of the 5th Biennial Conference of the Institutes of Technology and Polytechnics of New Zealand Research Forum 2-3 October. Wellington: Institutes of Technology and Polytechnics New Zealand. 